\title{
Tratamiento multimodal: nuevo horizonte en Urología Oncológica. Ocaso de la praxis y concepto de monoterapia
}

\author{
Gelabert Mas A. \\ Servicio y Cátedra de Urología. Hospital del Mar. UAB. Barcelona.
}

Actas Urol Esp. 2008;32(8):771-772

$\mathrm{T}$ odo indica que estamos al final de un tiempo en que a cada paciente le diagnosticaba y asumía toda decisión terapéutica un solo médico, quien prescribía casi siempre un tratamiento con un solo fármaco o a veces varios (pocos), dirigidos al diagnóstico que él solo había efectuado; como ejemplo paradigmático está la patología infecciosa genitourinaria. El paciente acudía por un síndrome clínico de infección urinaria, el médico, en este caso el urólogo, diagnosticaba certeramente el proceso y le prescribía el antibiótico adecuado, a lo más algún otro medicamento acompañante, muy pocas veces, para paliar o evitar los efectos secundarios del antibiótico en su formulación galénica.

El diagnóstico era exacto en su aspecto etiológico y de ahí que la prescripción también fuera exacta en función del germen, pero lo cierto es que pocas veces se valoraba todo el entorno del proceso morboso, la afectación de otros órganos o sistemas, y no se prescribía para disminuir o evitar los efectos colaterales del proceso infeccioso, y hay que precisar que también se desconocía en gran medida la complejidad multisistémica de la patología infecciosa; es decir, estábamos frente a un comportamiento diagnósticoterapéutico monoterápico para un proceso patológico que ahora ya asumimos que es complejo y que entonces era valorado como única diana a tener en cuenta.

Pero también si nos retrotraemos algunos años atrás, algo más de una década, y nos fijamos en diagnósticos de patología tumoral urológica, y tomando el ejemplo del Cáncer de Próstata, vemos que el urólogo efectuaba, y efectúa aún, el diagnóstico preciso, como siempre ha sido, y prescribía el tratamiento adecuado, generalmente Hormonoterapia ya que la inmensa mayoría de los diagnósticos se efectuaban en estadios localmente avanzados o diseminados y hormonosensibles.

Entonces: ¿cuál es el problema ahora?, o ¿cuál es la reflexión actual?.
Desde que el concepto de Unidades Funcionales empezó su andadura como una manera de abordar las orientaciones diagnósticas y terapéuticas en patologías oncológicas, básicamente, pero no únicas, tal es el caso de la patología funcional del suelo pélvico, se ha ido extendiendo el cambio cultural de manera paulatina en muchos centros hospitalarios, si bien es cierto que con velocidades muy desiguales, dependiendo fundamentalmente de los profesionales, en función de su adhesión o asimilación de una nueva filosofía asistencial basada en evidencias científicas. Las Unidades Funcionales han demostrado una mejora en el ejercicio terapéutico de las patologías que abordan en su ámbito, y la transforman en lo que se viene llamando excelencia asistencial, reñido con el ejercicio personalista de la decisión.

Se ha avanzado mucho en el conocimiento de la complejidad de las patologías en cuestión y asistimos al hecho de que el diagnóstico no es un simple nombre: cáncer de..., incontinencia urinaria..., sino que conlleva todo un cortejo de problemáticas: multiorgánicas, funcionales, genéticas y psíquicas. Este avance ha sido posible porque la discusión entre distintos profesionales que entienden del mismo proceso bajo aspectos distintos: urólogos, oncólogos médicos, ginecólogos, radioterapeutas, patólogos, digestólogos, cirujanos digestivos, entre otros, enriquece el diagnóstico y éste se ve enfocado bajo los distintos ángulos de análisis de cada profesional especialista quien aporta sus conocimientos y experiencia diferenciada, es decir, se analiza y se explici$\tan$ aspectos distintos que intervienen en el mismo proceso. El paciente es valorado como un todo desde un aspecto multiprofesional, con este proceder se asegura que se tratará la patología de la manera más efectiva, con la máxima evidencia científica ya que se detectan, tratan y corrigen todos los frentes de la misma y por ello las posibilidades de éxito son mayores. 
Estamos seguros que la semilla está bien sembrada y con el tiempo dará sus frutos cuya calidad dependerá en gran medida del terreno profesional.

A medida que conocemos con más profundidad los mecanismos genéticos que caracterizan la tumorogénesis, sabemos que existen distintas rutas moleculares sobre las que podemos incidir para modificar los procesos metabólicos de la célula neoplásica; además y ello adquiere cada vez más importancia: el escape metabólico de la célula neoplásica. En unos tumores de manera lenta y en otros de manera rápida.

Un ejemplo de los primeros lo tenemos en la Hormonorrefractariedad a que inexorablemente llegan todos los cánceres de próstata, al hacerse resistente el RA, lo que explica la gran supervivencia de estos pacientes.

Y un ejemplo de los segundos, de adquisición de resistencia terapéutica rápida, lo tenemos en el Ca. Renal, cuyas receptores moleculares no tienen tanta solidez y en pocos meses dejen de ser efectivos, con lo que el intervalo libre de enfermedad es corto, relativamente.

Por lo tanto junto a los cambios de organización asistencial y a la luz de los nuevos conocimientos se impone una nueva realidad terapéutica: la terapia multimodal.

El concepto de tratamiento multimodal engloba varios aspectos:

a) Se enfoca el proceso patológico desde ópticas y aspectos distintos; cada profesional razona el interés de su indicación en atención a uno o unos efectos colaterales, o no deseados, o concomitantes, del proceso principal y que por lo tanto deben ser atendidos adecuadamente en aras a la mejor calidad terapéutica;

b) Algo tan importante como la jerarquía que debe establecerse entre los distintos tratamientos prescritos; se establece una prevalencia cronológica de los mismos ya que de la discusión interprofesio- nal se valora de manera más exacta en que momento evolutivo se encuentra el proceso patológico y por ello se jerarquizan las prescripciones.

c) Esta estrategia asistencial posibilita que todos los pacientes tengan el mejor tratamiento posible a la luz de la mejor evidencia científica, hace efectiva la equidad asistencial; evita el conocido "yo lo trato así..., porque yo creo..." y se sustituye por "el mejor tratamiento recomendado con nivel de evidencia A es..."

En relación a esta última reflexión tenemos un modelo patológico, el Cáncer de Próstata, donde queda bien explícita esta nueva situación durante el seguimiento de los pacientes afectos de esta patología, los interrogantes son muchos:

- a este paciente ¿cuál es la terapia de intención curativa más adecuada?

- ¿ en qué momento se debe iniciar el tratamiento: precoz o diferido?

- ¿en qué momento iniciar la radioterapia adyuvante en los márgenes positivos?

- ¿hormonoterapia adyuvante a la radioterapia?; ¿qué duración?

- hormonoterapia de segunda línea: ¿cuándo iniciarla?

- ¿hormonoterapia de tercera línea: ¿si-no?

- ¿cuándo es el momento ideal para iniciar la quimioterapia?

- ¿cuándo iniciar la terapéutica con Bifosfonatos para disminuir los ERES?

Estas cuestiones y otras que cada día están en el ambiente en las sesiones conjuntas, obligan a establecer unas claras decisiones fruto de la discusión multidisciplinar.

Correspondencia autor: Dr. A. Gelabert Mas

Servicio y Cátedra de Urología. Hospital del Mar. UAB.

Passeig Marítim, 25-29 - 08003 Barcelona. Tel.: 932483000

Correspondencia autor: agelabert@imas.imim.es

Información artículo: Editorial 